\title{
Transcendental Philosophy and the Problem of Necessity in a Contingent World
}

\author{
Julia Jansen \\ KU Leuven \\ Julia.Jansen@hiw.kuleuven.be
}

\begin{abstract}
In this article I draw out a fundamental difference between Kant's and Husserl's take on the problem of necessity in a contingent world. I do so by investigating in detail a well-known common feature of both philosophies, namely a basic understanding of necessary laws of objectivity and cognition in terms of necessary unities of synthesized manifolds. The fundamental difference between Kant and Husserl that I trace here concerns the radically different ways in which the two philosophers understand the origin of unity. While Kant maintains that all necessary unity, also of the contingently given, has its origin in the "synthetic unity of the understanding", Husserl describes how it emerges in and from the given itself in "syntheses of coinciding". As a result, the Kantian account leaves us with the famous conclusion that reason only finds in the contingent world those necessities that it has itself put into it, while, according to Husserl, rigorous science identifies and describes necessities, i.e., necessary unities of synthesized manifolds, in a systematic course of genuine discovery.
\end{abstract}

\section{Introduction}

That the problem of necessity is of utmost importance for both Kant and Husserl is obvious. It lies at the heart of the fundamental question of whether and how "rigorous science" may be saved from the threat of relativism, where rigorous science is understood as a system of truths that are universal and necessary (Kant) or essential and apodictic (Husserl). The problem received its wider social urgency, already in Kant's time, from the increasing awareness, even on the side of the general public, of the fundamental contingency of

Metodo. International Studies in Phenomenology and Philosophy Special Issue, n. I, ch. 1 (2015)

ISSN 2281-9177 
human life, which was no longer counterbalanced by an unquestionable order secured by an omnipotent, omniscient God. It received its concrete scientific urgency due to the impact of Humean skepticism on philosophical debate as well as due to the increasing dominance of the natural scientific paradigm, which promoted the accumulation of observable contingent matters-of-fact. For Kant as well as for Husserl, then, one task of transcendental philosophy is to identify and validate those truths that retain their necessity amidst and in reference to the contingencies of nature and experience. At issue is therefore not primarily the necessity of analytic truths, which concern the laws of thinking as formulated by formal logic, but the necessity of truths about the contingent world of experience, i.e., the necessity of synthetic truths. Both Kant and Husserl believe that this question can only be answered in reference to the structures of consciousness, which means that transcendental philosophy is, both in its more Kantian or in its later Husserlian strands, inextricably linked with the so-called "Copernican Revolution". According to this model, while events in space and time are undeniably contingent, transcendental philosophy aims at uncovering the necessary conditions of those events not directly, but through an analysis of the necessary conditions of their knowability. The attempt to determine necessary truths about objects without reference to these latter conditions is cast aside as "speculative" (Kant) or "constructivist" (Husserl) metaphysics and replaced by the attempt to determine a priori truths about how objects can be known, or how they can appear to consciousness. This also entails a defense of the transcendental project against reductions to "empirical" (Kant) or "naturalist" (Husserl) paradigms and a commitment to a model of "rigorous science" that depends on a critical clarification of the essential structures and activities of the cognizing subject.

However, there are also obvious differences between Kant's and Husserl's account, for example, in respect to their differing notions of the apriori; their fundamentally different methods; and their views on what aspects of subjectivity are relevant to a transcendental account. Here I focus on another of difference. It concerns the distinct ways in which Kant and Husserl deal with the problem of necessity in the contigent world in terms of the relation between a given sensible manifold and its unity. Generally speaking, they agree this much: While the world is given as a sensible manifold, and, insofar as it is given, it is always contingent, its unity may carry, and may be known to carry, necessity, in which case the unified manifold attains objectivity. Here is where we find a fundamental difference. To put it briefly: Kant thinks of a necessary unity as a unity that receives its necessity "top down" from the "highest point" of reason, i.e., from the transcendental unity of apperception. Husserl, on the

Metodo. International Studies in Phenomenology and Philosophy Special Issue, n. I, ch. 1 (2015) 
contrary, thinks of unity "laterally", as a unity of "coincidence (Deckung)", which enables apriori insight not only into necessities that "reason itself produces according to its own plan» (B xiii), as Kant famously claimed, but also into necessities reason genuinely discovers.

The Kantian account is well-known, but for sake of contrast, I summarize it in the first section and show how much and, most importantly, why it relies on the idea that necessary unity in sensible manifolds, and thus any necessity observable in what is contingently given, is produced by an "effort" of the understanding. In the more extended second section, I first reconstruct Husserl's counter-position, which makes use of the idea of a passive "synthesis of coincidence (Deckungssynthese)" in an attempt to account for unity that inheres in the perceptually given. Then, I discuss Husserl's account of the necessary laws that regulate the perceptually given and that - contrary to Kant's position - also originate in it, and not in reason. Finally, I show that Husserl's idea of passive coincidence is operative not only on the level of the perceptually given, but also on the level of cognition, and even a priori cognition, namely in eidetic intuition. I argue that this constitutes a profound difference, not only with regards to the different methods of transcendental philosophy, but also with regards to their views on the question of necessity in a contingent world.

\section{Kant on Necessity in the Given}

Kant's account of the relation between a sensible manifold and its unity reflects his separation between the faculties of understanding and sensibility. And yet, at first glance, the two faculties appear to be equal. While «pure intuition contains only the form under which something is intuited, [...] a pure concept contains solely the form of the thought of an object as such»(A51/B75). However, form does not eo ipso carry unity for Kant; it may "lie in the mind" independently of any given manifold, whereas unity is always unity of a manifold. As such, unity presupposes synthesis; it is unity of a synthesized manifold. Since synthesis, as «an act of [the subject's] self-activity», is, in Kant's view, an "act of understanding» (B130), unity, unlike form, demands the understanding. This is true even in the case of the "unity [...] that belongs to space and time» (B160 n.), that is, for the intuitive unity of a sensible «manifold, outside or within us»; for while that unity is "given a priori», it is given, as Kant writes somewhat cryptically, «along with (not in) these intuitions» (B 161). A «form of intuition gives us merely manifold» (B160 n.) 
while the unity displayed in a formal intuition already involves the understanding in some capacity. The distinction between a form of intuition and a formal intuition thus gives us a good idea of what the term "unity" actually delivers: Unity, for Kant, is what constitutes objectivity. Unity in intuition, which is produced by a sensible synthesis, gives intuitions of objects; unity of concepts, which is produced by an intellectual synthesis, gives concepts of objects. In both cases, the unity itself depends on a «higher» unity (B131), namely on the "original synthetic unity of apperception», which is the unity of possible self-consciousness.

According to Kant, I become aware of my "identical self" not by looking into my soul, or by simply thinking " $\mathrm{I}$ ", but only «as regards the manifold of the presentations given to me in an intuition, because I call them one and all my presentations» (B 135). Whether I ever do (call them that) or not «depends on circumstances or empirical conditions» (B139); it «is entirely contingent» (B140). However, if I ever were unable to call my representations mine, then, Kant famously holds, they would «either [...] be impossible, or at least would be nothing for me» (B 132). Thus, the unity that guarantees the possibility of selfconsciousness is itself a necessity: «The I think must be capable of accompanying all my presentations» (B 131; my italics), and thus the original synthetic unity of apperception is necessarily valid. It may be called «objective» because it «is the unity whereby everything manifold given in an intuition is united in a concept of the object» (B139). In fact, an object, for Kant, is nothing other than «that in whose concept the manifold of a given intuition is united» (B 137).

Kant here speaks of conceptual unity because even though he does not deny that there is unity in intuition (on the contrary, his entire transcendental deduction ultimately rests on it), he does not think that this unity originates in sensibility. The origin of unity is the transcendental unity of self-consciousness, but it is brought about by the understanding, "which itself is nothing more than the power to combine a priori and to bring the manifold of given intuitions under the unity of apperception» (B 135). In other words, the understanding prescribes that manifolds are synthesized in such a way that their "unity", i.e., the rule or "function" of their unifying synthesis, can be thought coherently ("in one consciousness") by means of a concept. This also means that these "unified" manifolds can be recognized as presentations of objects.

Whatever we are given through the senses is contingent, i.e., out of our control. Kant is clear about that. We cannot introduce unity at will (for example, by means of judgment) into an otherwise completely arbitrary manifold, which - due to the fundamental separation of the faculties - is in

Metodo. International Studies in Phenomenology and Philosophy Special Issue, n. I, ch. 1 (2015) 
itself foreign to thought. The only reason why we can a priori think conditions of possibility for objects of experience at all, is that our sensibility is not merely receptive. It also has forms, namely the forms of intuition, time and space. That means that there are temporal and spatial a priori manifolds, which are immune to the contingency of the given. Secondly, our sensibility also has imagination. We may apriori think of such formal temporal manifolds as unified, and, upon such instigation of the understanding, the productive imagination is able a priori to generate corresponding unified formal intuitions, i.e., schemata of time or space (B 176/A 137 f.; see B 160 n.). Since the empirical synthesis of apprehension, i.e., the synthesis of contingent sensible manifolds which generates perceptions, is subject to time and space as its forms, it is also subject to the same transcendental unity (B 160) that is displayed in formal intuitions of time and space. As a result, even perceptions, which are and remain contingent with respect to what is given in them, are subject to this necessary unity. Since the categories are but different ways of "expressing" this "unity of understanding" (B xvii), we may also say that perceptions are "subject to the categories":

all synthesis, the synthesis through which even perception becomes possible, is subject to the categories; and since experience is cognition through connected perceptions, the categories are conditions of the possibility of experience and hence hold a priori also for all objects of experience. (B 161)

This, according to Kant, explains, on the one hand, why we can a priori know the universal form and unity of all possible objects of experience (i.e., that they are causally related, that they are structured in terms of substance and accidents, and so forth), and, on the other hand, why thereby «reason has insight only into that which it itself produces according to its own design» (B xiii). Only with regards to objects of possible experience can we state that they necessarily and universally accord with the categories because the categories are concrete expressions of the subjective condition of experience that is, due to transcendental constraints on the synthesis of apprehension, "objectively valid": the objective unity of self-consciousness (B 139f.).

The fact that objects of possible experience are thus structured in accordance with the forms of thought (i.e., the categories) does not mean, for Kant, that we in any way interfere with what is given to us. Although «all we cognize a priori about things is what we ourselves put into them» (B xviii), we do not structure, form, construct, or even produce the given. The point is rather that objects of possible experience, that is, objects regarded with respect to how they can be 
known to us, must display this structure, or unity. With regards to their existence we cannot know anything about them a priori. With regards to their nature as things-in-themselves, i.e., with regards to what they are like independently from us, we cannot know anything at all. However, with regards to their knowability, i.e., with regards to the formal conditions of how they appear to us formally ("formaliter spectata", B 165), we can and, if we believe Kant, do know their structure a priori.

Kant's powerful conclusion also betrays a powerful assumption (itself a result, paradoxically, of his attempt to avoid assumptions). Beyond the, as he likes to emphasize, exactly twelve categories and beyond the two forms of sensibility, which owe their necessary validity for the given to their being necessary conditions for the cognition of the given, the given qua given is radically contingent and has no necessary order whatsoever. ${ }^{1}$ The given is given «without having to refer necessarily to functions of understanding» (B 122/ A 89) at all, which is why it is at least possible that «appearances might possibly be of such a character that the understanding would not find them to conform at all to the conditions of its unity. Everything might then $\{\ldots\}$ be confused» (B 123/ A 90; my italics).

\section{Husserl On Necessity in the Given}

Husserl famously praises the transcendental deduction and the concept of synthesis as two of «Kant's greatest intuitions», which - unbeknownst to Kant, of course - already take place «on a phenomenological ground» (Hua 3, $118 \mathrm{f}$.). However, Husserl considers the unity of the sensible not an "effect of the understanding", but an element of the given itself. It is important to note how radically Husserl departs from Kant already on this point. Kant assumes that what is merely given (when we abstract from any effort by the understanding) is the «effect of an object on our capacity for presentation, insofar as we are affected by the object», viz. sensation (B34/A20). However, what is intuitively given is not reducible to sensation, and even what is given in perception already depends on syntheses that are subject to the transcendental unity

1 Given Kant's account we actually must distinguish between what is perceptually given to us, which is already subject to the categories and thus subject to necessary laws, and that which is "merely" given in abstraction from the "influence of the understanding", namely the sheer matter of intuition which is radically contingent. However, since the perceptually given has, as it were, no laws of its own, we can also say more generally that the given is insofar as it is given contingent for Kant.

Metodo. International Studies in Phenomenology and Philosophy Special Issue, n. I, ch. 1 (2015) 
apperception. Hence Kant's notion of synthesis is based on the idea that «we cannot present anything as combined in the object without ourselves having combined it beforehand» (B 130). This is why, for Kant, an object is nothing other than «that in the concept of which the manifold of a given intuition is united» (B 137). This claim only makes sense within the framework of Kant's distinction between objects as appearances and things-in-themselves. The notions of synthesis and of its unity acquire a very different meaning in the phenomenology of Husserl, who rejects that very distinction as «mythology» (Hua 7, 235; Hua 36, 66).

In phenomenological analysis, Husserl finds no indication of a distinction between the world as it appears to us and a distinct realm of noumena. What he believes is evident in a correlation between consciousness and world. This means not only that consciousness is always "consciousness of..." but also that the world is always "world for consciousness". Husserl thus does not differentiate being into "being for us" and "being in-itself"; rather, "to the essence of all being belongs a relation to consciousness» (Hua 36, 36 - my italics). In other words, an «object that is, but is not and in principle could not be an object of a consciousness, is pure non-sense» (Hua 11, 19f.). Husserl's discovery of this "correlational Apriori" has significant consequences for his notion of constitution, which provides the framework for his reappropriation of Kant's concept of synthesis. First, every constituting by consciousness is at the same time a self-manifestation of world as it is, not only as it appears to us. Second, this self-manifestation need not correspond to any principles governing the intellectual sphere of consciousness.

When there is no active intellectual engagement by consciousness (for example, in passive perception), the world that is given (for example, perceptually) has no conceptual or propositional order. It is not, as Kant thought, subject to the "laws of the understanding", but the inverse is true: Any concept or proposition referring to the world is ultimately rooted in this basic experience of the given, namely as its conceptualization and its idealization. Therefore, while Husserl agrees that the question of object constitution is one of the most fundamental problems of transcendental philosophy, he disagrees with Kant's view that it is a matter of "constitutive principles of the understanding" and instead moves the correlative process of constitution center stage. ${ }^{2}$

2 Although it is common now to speak of "the problem of constitution in Kant", the term "constitution" only became a general terminus technicus in the early $20^{\text {th }}$ century. Kant actually does not use it explicitly. He uses "constitutive" with regards to principles of the understanding, but would not speak of synthesis as "constitution".

Metodo. International Studies in Phenomenology and Philosophy Special Issue, n. 1, ch. 1 (2015) 
That fundamental difference notwithstanding, Husserl certainly agrees with Kant's insight that "synthesis of a manifold" (whether this manifold is given empirically or a priori) is what first gives rise to a cognition (A 77/B 103) and, like Kant, he understands constitution as dependent on the fundamental question of unity in a synthesized manifold. In fact, at first glance, Kant's claim that synthesis is required for anything «to become an object for me» because "otherwise, and without that synthesis, the manifold would not unite in one consciousness» (B 138) may appear almost indistinguishable from Husserl's claim that objects can only ever «take shape as synthetic unities» (Hua 17, 147). And indeed, as is well known, Husserl himself draws attention to his proximity to Kant's problematic:

Kant searches in subjectivity [...] for the ultimate explication of the sense of objectivity that is cognized in cognition. To this extent we agree with Kant [...]. (Hua 7, 386 - my translation)

However, a closer look reveals a profound distance between Kant and Husserl. Objects, for Husserl, «take shape as synthetic unities in the mode "they themselves"» (Hua 17, 147 - my italics), not as appearances. Moreover, Husserl corrects "subjectivity" to "the correlation between subjectivity and objectivity» (Hua 7, 386 - my translation). ${ }^{3}$ This also means that despite his enthusiasm for Kant's notion of synthesis, the idea of a "productive imagination", which is central to Kant's transcendental deduction, never could sit right with Husserl who firmly rejects the idea that consciousness "produces" the given, or even the unity of the given. ${ }^{4}$

Husserl also rejects from the start any understanding of synthesis as a psychological process in which a "perceptual image" is constructed out of discrete, non-intentional sense impressions. Already in the Philosophy of Arithmetics, he works with the idea, which will become a leitmotif throughout his work, that awareness of objects involves the direct apprehension of complex wholes, or unified manifolds, even without requiring higher level intellectual acts, such as judgments, or mediating representations, such as images. Initially led by

3 The complete passage reads: «Kant sucht in der Subjectivitaet bzw. in der Korrelation zwischen Subjectivität und Objectivem die letzte Bestimmung des Sinnes der Objektivität, die durch Erkenntnis erkannt wird. Insofern sind wir mit Kant einig...»

4 However, while he rejects the term, he is inspired by Kant's «profound but obscure doctrine» (Hua 11, 275), from which he takes that cognition requires more than predicative synthesis and judgment. In fact, Husserl appears to have understood his account of passive constitution as the proper clarification of productive synthesis that Kant himself was unable give (cf. Hua 11, 276).

Metodo. International Studies in Phenomenology and Philosophy Special Issue, n. I, ch. 1 (2015) 
materialist interpretations, given, for example, by the neo-Kantian Friedrich Lange ${ }^{5}$ Husserl therefore takes exception to Kant's claim that synthesis refers not only to a «sense of the unity of the parts and the whole» but also to a "sense of the mental activity ("action of the understanding") of combining" (Hua 12, 38). Husserl accuses both Lange and Kant of pursuing «predominantly metaphysical tendencies» which result in a constructivist account. Husserl summarizes the target of his objections thus:

Consciousness itself, and thereby subjectivity, is supposed first to originate out of unconscious impressions through a process of synthesis at the highest level. Thus is the unity of consciousness explained [by Lange and Kant]. (Hua 12, 40)

Husserl thus rejects Kant's account as «untenable» because it is «based on essential misunderstandings» regarding the nature of synthesis. ${ }^{6}$ In his view, Kant misconstrued synthesis as the "first act of the understanding" because he simply «failed to notice that many combinations of content are given to us where no trace of a synthesizing activity that produces connectedness is to be found» (Hua 12, 41 - my italics). This early insight of Husserl's is crucial and will remain important throughout his work, most explicitly in his notion of "passive synthesis". According to this insight, Kant, the father of "critical" philosophy, appears to have been misled by his own metaphysical assumptions, which prevented him from seeing what Husserl considers obvious: that «experience, and it alone is decisive here, shows nothing of such "creative" processes» (Hua 12, 42). ${ }^{7}$ Husserl therefore sides with Natorp (and, he believes, against Kant), in cautioning us not to misunderstand the frequent talk of "mental acts" and "acts of consciousness" as necessarily implying the doings of a spontaneous Ego. "In talking of "acts"», Husserl already warns in the Logical Investigations, «we must steer clear of the word's original meaning: all thought of activity must be rigidly excluded» (Hua 19, 393 [V § 13]).

5 In the Philosophy of Arithmetic, Husserl extensively cites Friedrich Lange's Geschichte des Materialismus und Kritik seiner Bedeutung in der Gegenwart (Baedeker: Iserlohn, 1866) as well as his Logische Studien (Baedeker: Iserlohn, 1877).

6 The issue here is not what Kant's position actually was. In fact, it is quite clear that Husserl's reading is tendentious. However, Husserl's understanding is what matters here, not the question of whether that understanding was accurate.

7 Husserl is, however, not always being clear enough on this point. See, for example, his description of sense constitution in his lectures on Phenomenological Psychology, where he says: «ideal objects confront us as subjectively produced formations in the lived experience and doing of the forming» (Hua 9, 25). Ideal objects are the "products" of intellectual operations (more of this later), but they are not mere fabrications either.

Metodo. International Studies in Phenomenology and Philosophy Special Issue, n. 1, ch. 1 (2015) 
What's more, there is, as far as Husserl can see, no phenomenologically legitimate reason to suppose that the origin of unity of sensible syntheses does not lie in themselves. As we have just seen, Husserl discards the idea, which is crucial for Kant, that synthesis is «an act of [the subject's] self-activity» and as such necessarily an "action of the understanding» (B130). Instead he observes syntheses as occurring in different modes (active as well as passive), on different levels (pre-predicative and predicative), and with regards to different kinds of objects (real and ideal, individual and general, etc.). I cannot here trace Husserl's observation regarding all of these different aspects of a full account of synthesis, but I will restrict myself to the distinctly un-Kantian idea that syntheses may have unity that is not the result of an "effort" of the subject, let alone an "effort of the understanding". According to Husserl, syntheses also acquire unity by coinciding (Sich-decken ${ }^{8}$ ). In such coinciding, objects, i.e., unities of syntheses, are experienced as given, rather than made; they are discovered, and not produced. As I discuss in what follows, Husserl thinks of coincidence (Deckung) as a unity (Deckungseinheit) ${ }^{9}$ that unfolds in continuous syntheses according to essential laws that can be identified. As a result, he thinks of "the given" in a very different way than Kant. Whereas Kant considers the given, insofar as it is given, as radically contingent, that is, as lacking any necessary order whatsoever; Husserl believes that the given itself is regulated in essential, and therewith, in necessary ways.

The notion of "synthesis of coinciding" (Deckungssynthese) is recognized as an important element of Husserlian phenomenology overall. Already in the Logical Investigations of 1901, for example, he talks about the "fulfillment" of signitive intentions by intuitive intentions with which they "coincide". For example, in the 6th investigation, the "synthesis of coincidence" refers to the process by which a signification acquires its evident fulfillment. But Husserl uses the term "Deckung" also in late texts, such as the Cartesian Meditations (written in 1929) or the «Origin of Geometry», which Husserl wrote in 1936

8 The fact that this verb is reflexive in German emphasizes nicely that it refers to a kind of "self-unifying" process. Two things "decken sich"; they come together without being brought or put together by a third thing (such as a tertium comparationis or a "combining" subject).

9 One inspiration for this idea is obviously Carl Stumpf's concept of "fusion (Verschmelzung)", which also lacks active "combining". Stumpf uses the fusion of tones in a chord as an example. Although each tone can also be heard without the other, if «they are sensed at the same time, it is impossible to avoid sensing them as a whole, to avoid sensing them in the relation of fusion» (STUMPF 1890, 65). Husserl makes reference to processes of fusion through out his work.

Metodo. International Studies in Phenomenology and Philosophy Special Issue, n. I, ch. 1 (2015) 
and which speaks of coincidence as the self-evidence of identity. ${ }^{10}$ In fact, the idea of "coincidence" is operative in all of Husserl's writings; its fundamental significance for his thinking overall cannot be emphasized enough. In what follows, I only draw out some ways in which it marks a profound difference between his phenomenology and Kant's philosophy regarding the question of this essay, namely the question of necessity within the contingently given.

\subsection{Coincidence in the Perceptually Given: Husserl's Constitutive Analysis}

Given that consciousness, as Kant had also observed, is always temporal and can thus only be conscious of anything in a continuous flux of time, one may wonder how any sense of unity in the manifold of the temporally given could ever arise. Even if we keep things simple and consider the example of listening to a melody, we might think that temporal succession is irreconcilable with the idea of a unified object.

[...] if in the course of perceptual lived-experiencing, the respective momentary lived-experiencing has gone over into a new one, thus, past by, then the new one brings to consciousness precisely a new tonal content: Every momentary phase of perceiving [brings to consciousness] its content and no other. By no means could the consciousness of a tonal process, of a melody arise. (Hua 11, 315)

And yet, the paradox that arises for theoretical reflection notwithstanding, we have irrefutable experiential evidence for the emergence of unity in the continuous unfolding of new phases of perception. The question is not whether we perceive unified objects - we evidently do - but how we do it.

But we have this consciousness, and during the perceiving, [we have it] in every moment; we are not only conscious of the momentary resounding tone or even of its momentary phase, but [we are conscious of] the protracted tone itself and the melody - to be sure, as a constant becoming, constant flowing and elapse. (Hua 11, 315)

The apparent paradox, it turns out, is the result of a false conception of experience. When we pay attention to our experience of objects, we find that the flux of consciousness is not given as a mere sequence of momentary "nowpoints". If it were, it would never allow for the constitution of a continuous unity, neither of one enduring object, nor of one continuous stream of consciousness. Thankfully, this is a problem only for abstract thought. Indivisible "now-points" are "sheer fictions that lead to absurdities» (Hua 10,

10 Cf. Husserl 1970, 360.

Metodo. International Studies in Phenomenology and Philosophy Special Issue, n. 1, ch. 1 (2015) 
169). Careful analyses of time-consciousness show that each Now has a "horizon" of retention (of what is present as just having-been) and a "horizon" of protention (of what is present as about-to-come). In this horizontal structure, consciousness actually has a hold on continuity within the flux. However, and this is how this becomes relevant to our discussion here, this "hold" is not the result of an explicit effort on the part of consciousness. Retention is not the same as the "act" of remembering; and protention is not the same as the act of expecting. Consciousness is passive in this unfolding of an «unbroken continuity» (ibid.).

Perceptual objects show themselves to consciousness in an equally "horizonal" structure, and they do so too without any active "combining" by consciousness, let alone any "effort of the understanding". Here we get to the core of Husserl's account of the "given", namely his analyses of the emergence of unity within the given in passive syntheses of consciousness. Consciousness is "passive" here in a double sense: It does not actively perform any operations on a "merely" given (e.g., on sense data, impressions, or the like); and it experiences the "given" as asserting itself. ${ }^{11}$ The "given", to be more precise, gives itself as "pregiven", i.e., as being prior to and independent from any attempts by consciousness to grasp it.

[O]bjects are pregiven [vorgegeben] to the experiencing subject passively in experience, and are only experiencable through pregivenness in such a way that the subject merely exercises acts of receptivity, acts of grasping and then acts of explicating something that is already there, something that already appears ... this latter realm of objects must precede all activity in general ... (Hua 11, 291).

However, when we suspend our conceptions of objectivity, we find that the "pregiven" always appears in "perspectival adumbration", which "manifests the ... object from one side» only. «Every aspect, every continuity of single adumbrations, regardless how far this continuity may extend, offers us only sides.» (Hua 11, 3) Abstract thought finds in this succession of "profiles" the same paradox it found in the stream of consciousness. And yet, here as there, experiential evidence shows the emergence of unity: an «objective sense exhibits itself as unity [in] the unending manifolds of possible appearances» (ibid.), in relation to which we experience each profile as belonging to an unfolding manifold of profiles of one and the same thing.

No explanation or "deduction" is given, and, according to the phenomenolo-

11 The difference is subtle but important; for the "passivity" of consciousness is not a simple inactivity, but also - as Kant had acknowledged already - a receptivity.

Metodo. International Studies in Phenomenology and Philosophy Special Issue, n. I, ch. 1 (2015) 
gical method, none is needed - neither for the "transcendence" of the object (as distinct from its the varying presentations we can have of it), nor for its unity (as one object appearing in a manifold of adumbrations). While Husserl thereby certainly disappoints Kantian expectations, he delivers what he believes is the only legitimate "proof": methodologically "purified"12 experiential evidence, which verifies what Husserl had already observed in the Philosophy of Arithmetics: «experience [...] shows nothing of such "creative" processes» (Hua $12,42)$ as the ones Kant had "deduced". While synthesis generates a "sense of the unity», it does not require a "sense of the mental activity ("action of the understanding") of combining» (Hua 12, 38). ${ }^{13}$ Rather, what we learn in reflection on perception is that the "world constitutes itself as a sensuous unity" (Hua 19, 316, [VI, § 65] - my italics). This "idea", then, is not a dogmatic assumption, or simply Husserl's best guess. It is an insight gained from experiential evidence: the world is given and experienced as a pregiven unity. This, as Husserl states emphatically, "we do not merely think, but we see it to be true» (Hua 19, 317 [VI, § 65]) - even though not all our experiences fit together harmoniously and even though not everything in the world makes sense to us.

Of course,

there are breaks here and there, discordances; many a partial belief is crossed out and becomes a disbelief, many a doubt arises and remains unsolved for a time, and so forth. But ultimately, [...] if the world gets an altered sense through many particular changes, there is a unity of synthesis in spite of such alterations running through the successive sequence of universal intendings of the world - it is one in its particular details [...]; it is in itself the same world. (Hua 11, 101; cf. § $107-$ my italics)

Free from the metaphysical assumptions with which Husserl sees Kant entering his transcendental deduction - first among them the separation of sensibility and understanding as fundamentally different sources of cognition, of which only the understanding can be the source of unity - Husserl's task is

12 There is no room here to get into the details of Husserl's method. I only want to remind the reader that a number of methodic steps are required in order to turn experience into phenomenological evidence, most importantly the epoché as well as the transcendental and eidetic reductions.

13 Thus, Husserl's notion of "passive synthesis" does not actually mark a discontinuity between his "early" and his "late" thought. It is better understood as the later, methodologically substantiated, explication of his early insight «that many combinations of content are given to us where no trace of a synthesizing activity that produces connectedness is to be found» (Hua 12,41).

Metodo. International Studies in Phenomenology and Philosophy Special Issue, n. 1, ch. 1 (2015) 
one of tracking and describing the unity of the world (and the unity of the consciousness whose world it is) ${ }^{14}$ to the extent that we have evidence of that unity. Rather than coming up with a transcendental deduction of the supposed "extra-" or "super-worldly" origin of unity in the possibility of human rational self-consciousness, Husserl thus sets out to pay attention to the different levels in which it constitutes itself:

One requires no metaphysical or other theories to explain the agreement of the course of nature and the "native" regularities of the understanding. Instead of an explanation, one needs only a phenomenological clarification of meaning, thinking and knowing, and of the ideas and laws which spring from these. The world constitutes itself as a sensuous unity: its very meaning is to be the unity of actual and possible straightforward percepts. (Hua 19, 316 [VI, § 65] - my italics)

The unity of a perceptual object in the world manifests itself in a continuous synthesis of coincidence, which is a passive synthesis. That is to say, it occurs without necessary interference by the ego who may or may not engage actively with it, for example, by judging the perceptually given. Perception does not depent on an activity of the ego. The inverse is true. The passive synthesis of coincidences in the perceptually given, as Husserl explains in the Dingvorlesung, "must lie at the foundation in order for the [active] logical synthesis, that of identification, to produce the evident givenness of the identity of the objects appearing in the various perceptions» (Hua 7, 155 - my italics). And yet, coincidence is obviously not something that occurs in separation from consciousness. It is the synthesis in which the unity of the world constitutes itself as a world for consciousness; or, put differently, it is the initial evidence we have of unity in the perceptually given, which is given to us before we seek it.

In Husserl's eyes, then, the foregoing of a "rigorous" phenomenological analysis for the sake of an intellectual "deduction" is Kant's greatest failure. Looking for the "highest point" on which all unity hangs and thus philosophizing, as it were, "from above", Kant misses the evidence that the phenomenological method uncovers in experience itself.

To treat the intuitive self-grasping (Selbsterfassen), self-possessing (Selbsthaben), as a puzzle, that is, to fail to comprehend itself, means to philosophize about evidence top-down (von oben her) instead to look at evidence itself, to bring itself to evidence. (Hua 30, 326f. - my italics and translation)

14 Ultimately, Husserl's investigations of essences circulate around the attempt to establish the eidos "world" and the eidos "Ego" (see Hua 41).

Metodo. International Studies in Phenomenology and Philosophy Special Issue, n. I, ch. 1 (2015) 
Husserl thus replaces the Kantian idea of legitimation by means of transcendental arguments with his idea of validation through "intuitive selfgrasping", or phenomenological evidence. The extent of that evidence in Husserl's early work only permits the claim that the given carries unity and that this unity is not produced, but discovered by consciousness. For example, in the $6^{\text {th }}$ Logical Investigation Husserl observes:

[W]e may handle the thing from all sides in a continuous perceptual series, feeling it over as it were with our senses. But each single perception in this series is already a percept of the thing. Whether I look at this book from above or below, from inside or outside, I always see this book. It is always one and the same thing, and that not merely in some purely physical sense, but in the view of our percepts themselves. If individual properties dominate variably at each step, the thing itself as a perceived unity, is not in essence set up by some overreaching act founded upon these separate percepts. (Hua 19, 284 [VI, § 47]) ${ }^{15}$

In Ideas I, this insight becomes integral to Husserl's account of the noema's «relation to something objective» (Hua 3, 268), which involves two distinguishable moments. On the one hand, there is «this pure point of unity, this noematic "object simpliciter"»" the How of its determinations"» (Hua 3, 268). The noema in its full sense comprises both of these moments. Thus, the object is not "added in thought" to the sensible manifold, as Kant had maintained. Rather it is grasped in intuition. In thought, we abstract and separate the unity of the objet from the complex whole of the noema and thus wrongly construe an un-unified sensible manifold, which is in need of a unifying "act of the understanding". According to Husserl, this ignores the evident intrinsic reference of the noema to an object whose objectivity and transcendence is precisely based on the fact that it appears as one through the different "Hows of its determinations". In this transcendental account, Husserl maintains that the object is intuitively given as a regulative unity in a nexus of noemata that displays a «form of unification in agreement (Einigungsform der Verträglichkeit)» (Hua 3, 336). ${ }^{17}$ In this unity, every further noema is experienced as an "enrichment" of «the same physical thing-

15 It is easy to see that the problem of genesis was already "on the horizon" in Husserl's early work (cf. STEINBOCK 2001, xxxi), as Husserl himself acknowledges (see fn. 19).

16 In a footnote, Husserl adds in obvious reference to Kant's "transcendental object = X" (A 109): "“object simpliciter" $=$ X».

17 In the Cartesian Meditations, Husserl speaks of «rules of compossibility (Kompossibilität)» that regulate whether adumbrations can - simultaneously or successively - stand together (cf. Hua 1, 109).

Metodo. International Studies in Phenomenology and Philosophy Special Issue, n. 1, ch. 1 (2015) 
X» which remains open to further amplifications (or corrections) of its sense in further perceptions. Husserl concludes about the perceptually given: «the process is thus an endless one; accordingly, no intuitive seizing upon the physical thing-essence can be so complete that a further perception cannot noematially contribute anything new to it» (Hua 3, 311f.).

However, a transcendent object always appears in "adumbrations (Abschattungen)" or profiles, and never in its entirety, its adumbrations or profiles are experienced as precisely its adumbrations. The object is thus constituted

in certain concatenations of consciousness (Bewußtseinszusammenhängen) which themselves bear an intuitible (einsehbare) unity in so far as they, by virtue of their essence, carry with themselves the consciousness of an identical X. (Hua 3, 281 - trans. modified; my italics)

To capture the open-ended sense of the unity of an object across the multiplicity of its "adumbrations" or "profiles", Husserl refers to the "one and the same thing" as an «idea in the Kantian sense» (Hua 3, 297 f.). Although it can never be displayed fully in experience, it is evident in the regulative unity of coincidence which integrates new perceptions as further determinations of the same object. Thus, the object's «perfect givenness is nevertheless predesignated (vorgezeichnet) as "Idea"» (Hua 3, 298):

We first of all seize upon the unfulfilled idea of the physical thing and this individual physical thing as something which is given "so far," precisely as far as the harmonious intuition "reaches," but thereby remains determinable "in infinitum". The "etc." is an evident and absolutely indispensable moment in the thing-noema. (Hua 3, 312)

In other words, the object's objectivity is never fully given but is still, as an idea, an essential moment of the noema. It refers to the sense we have of the unity of "the "object (Gegenstand)", the "Object (Objekt)", the "Identical" » (Hua 3,271 ; cf. $\S 132$ ), which is always co-meant in the noema. In other words, the noema is unified "sense" insofar it presents certain determinations as determinations of an object that could be determined differently and that is thus irreducible to any particular way in which it is presented. In other words, a perceptual object is immediately experienced as something that could also be experienced differently (e.g., from different angles, from a greater distance, in a different light etc.); and it is experienced as one object by virtue of being noted as a unity of coinciding in different perceptions of it.

Husserl's later genetic phenomenology maybe understood as an attempt to

Metodo. International Studies in Phenomenology and Philosophy

Special Issue, n. I, ch. 1 (2015) 
bring this task to completion in what we may consider his alternative to Kant's transcendental deduction. Given Kant's belief that sensibility "by itself" delivers nothing but sense impressions, he must search for the origin of unity elsewhere. He thus deduces the necessity of an act that «gathers the elements for cognition and unites them to [form] a certain content» (A 78/ B 103) and is itself subject to the transcendental unity of apperception. By contrast, Husserl is forced, by the demands of his own method, to show the "origin" of unity understood as the process of its genesis - in experience itself. A clarification of the synthesis of coincidence in the perceptually given thus becomes the task of genetic phenomenology.

\subsection{The Laws of Coincidence in the Perceptually Given: Husserl's Genetic Analysis}

It makes sense that Husserl begins his lectures on Analyses Concerning Passive Synthesis with an observation that he considers firmly established in earlier analyses:

External perception is a constant pretension to accomplish something that, by its very nature, it is not in a position to accomplish. (Hua 11,3)

Its pretense is based on its involving not only elements that are "genuinely" perceived but also ones that are only "“co-meant" as co-present» (Hua 11, 4). It always includes profiles of the perceived object that are not actually seen, heard, touched, etc., but that are still present as just having-been perceived, or as just about-to-be perceived. Due to the continuous unfolding of perception in this «system of referential implications» (Hua 11,5), what is perceived is not merely a profile of a thing but the thing itself, even though it is in principle impossible «that a perceptual object could be given in the entirety of its sensibly intuitive features, literally, from all sides at once in a self-contained perception» (Hua 11, 3). In this sense, then, it lies in the essence of perception to outstrip itself; besides the manifold of perceptual profiles, it always also gives unity of that manifold.

This unity, however, is not at any time given completely, that is, it is never fully determined. Perceptual unity remains open in the continual course of further perceptions; it is a "horizonal" unity that at any moment includes echoes and anticipations of other possible profiles of the same object that could be brought to genuine appearance but currently are not. The "object" of perception is that which "coincides" as "the same" in that manifold of profiles. It thus lies in the essence of perceptual objects that they are

intertwined and permeated with an intentional empty horizon, that is, [that they are] surrounded by a halo of emptiness...that is not a 
nothingness, but an emptiness to be fill-out; [...] a determinable indeterminacy. (Hua 11, 6-my italics)

This might at first glance not look like much more than a (noematic) restatement of Husserl's analyses of internal time-consciousness. To the contrary, it far exceeds a purely formal analysis (in the Kantian vein) of the necessary conditions of unity. Indeed, the structure of time-consciousness is a necessary condition for the possibility of "coincidence" of the "same" in the continual course of perception. Only because consciousness and, correlatively, everything that can be something for consciousness is constituted in overlapping temporal horizons, can coincidences emerge at all (cf. Hua 11, 72f.). Even so, however, this temporal structure is purely formal. It is the structure «that necessarily connects all particular objects of which we become conscious originally in passivity as being», but it does so «no matter what their content may be and however else they may be constituted as unitary objects with respect to content» (Hua 11, 127 - my italics). A full clarification of coincidence, however, demands more. Husserl must show how it is not only formally but concretely possible for different profiles of objects and different contents of consciousness to coincide. In other words, he must explicate the eidetic laws of coincidence of different contents as adumbrations of a unitary objective sense.

Mere form is admittedly an abstraction, and thus from the very beginning the analysis of the intentionality of time-consciousness and its accomplishment is an analysis that works on [the level of] abstractions. It grasps, it is only interested in the necessary temporal form of all ... objects, or rather, correlatively it is only interested in the form of manifolds that constitute the temporal object... But what gives unity to the particular object with respect to content, what makes up the differences between each of them with respect to content... - the analysis of time alone cannot tell us, for it abstracts precisely from content. Thus, it does not give us any idea of the necessary synthetic structures of the streaming present and of the unitary stream of the presents... (Hua 11, 128 - my italics)

Husserl's analysis of passive syntheses thus complements his account of the form of time-consciousness with concrete analyses of coincidence. They reveal that the process of perception not only follows the formal structure "retentionimpression-protention" but also involves, with respect to its content, another fundamental relation, namely the relation between "emptiness" and "fullness". The profiles of the object that have just been, or are yet to come, are, Husserl puts it, "emptily" co-presented. They are undetermined (not "genuinely" perceived) but not completely unknown either. When I see an object's front, I

Metodo. International Studies in Phenomenology and Philosophy Special Issue, n. I, ch. 1 (2015) 
also see it as an object that has a backside, although I do not know what it looks like precisely before I look at it. Co-presented profiles are thus in a sense "prefigured". However, the significance of the relation between emptiness and fullness is missed when it is understood as a mere comparative statement that, as it were, compares two states "from the outside". Husserl's important insight is not merely that what is genuinely perceived is "fuller" in determinate content than what is only co-meant. It is rather that what is genuinely perceived in "fullness" always already "points ahead" to other, still "empty", profiles (in fact, that's sense of saying that they are "co-meant"), and that the thus "empty" horizon of perception is experienced as "to be fulfilled". Regarded "from inside" that relation, i.e., in terms of how it is experienced, it becomes evident as a teleological "dynamic transition" (Hua 11, 12) from empty intentions towards their fulfillment. This "dynamic transition" is itself based on a synthesis of coinciding, namely the coinciding of what is intended, first emptily and then fulfilled. Without that coincidence, the fulfillment would not be registered as such; it would not be taken as the fulfillment of what had been emptily intended. The teleological thrust of perception means that «perception drives at fashioning a unity» (Hua 11,9-my italics) and that it does so without being driven by a conscious Ego.

Husserl has thus identified another, non-formal transcendental condition of sensible unity: "Considered concretely, as in process, the perceptual livedexperience is continuously being fulfilled, and precisely for that reason, it is a unity of continual concordance» (Hua 11, 66 - my italics). The «directedness», or «striving» (Hua 11, 83 and passim) of perception, in turn, is in part due to fact that consciousness experiences the process of perception as an ongoing process of knowledge; «the process of fulfillment ... is also a process of knowing something more closely» (Hua 11,8), ${ }^{18}$ of gaining evidence for it. It has the form of motivation. What is genuinely perceived motivates other possible profiles; what is emptily given motivates its fulfillment in further acts of consciousness. However, while motivation can be identified as a concrete (as opposed to formal) and dynamic (as opposed to static) possibility condition, it does not yet give a full clarification of the emergence of coincidence, which Husserl attempts in his analyses of association.

18 In fact, to be more precise, the striving that is inherent in perception is two-fold. It is, on the one hand, a strictly speaking epistemic striving (Erkenntnisstreben) and, on the other hand, a striving after realization (Verwirklichungsstreben). That is, it is pulled towards a «verified intending (bewährte Meinung)» and towards a "grasping the object itself » (Hua 11, 88). Husserl thus finds in perception evidence in nuce for his notion of a "teleology of reason", which receives its fullest explication in the Crisis.

Metodo. International Studies in Phenomenology and Philosophy Special Issue, n. 1, ch. 1 (2015) 
Association is commonly understood as the process by which «something reminds one of something else» (HusserL 1973, 75 [\$16]). However, Husserl complements this empirical sense of association with a transcendental one. In this transcendental sense, "original", or "primary association" (Hua 11, 151, 273) is understood not as the process in which different contents are associated with one another but as the «immanent genesis» (HuSSERL 1973, 74 [§16]) of content itself. It refers to the different ways in which moments of consciousness "point to" one another and blend into one another as one - «even though there is still not an actual relation of indication by signs and designation» (Hua 11, 121). The various basic syntheses of association (e.g., similarity/contrast, fusion/prominence, etc.) thus are the concrete «preconditions of content» (Hua 11, 180). However, contrary to Kant's belief that these syntheses only have unity in virtue of the synthetic unity of apperception, Husserl discovers that they, and therewith the given that manifests in them, have their own regularities. In reflection, we are able to trace «a lawful regularity of immanent genesis that constantly belongs to consciousness in general» (Hua 11, 117; cf. HuSSERL 1973, §16). This makes association, in which different moments of consciousness come together as belonging together, «a fundamental concept belonging to transcendental phenomenology» (Hua 1, 114) ${ }^{19}$. It is neither the ultimate reason nor the constitutive principle, and also not a formal possibility condition, but the concrete process by which the given articulates itself into sensible unities of coinciding. To say that these are "sensible" unities is to say that they are experienced as unified prior to and independently from any intellectual understanding of them.

We have to keep in mind the same distinction here that was also needed to understand properly the relation between emptiness and fulfillment as an intentional relation. Equally, the significance of association, e.g., in terms of similarity, is missed when it is understood, as it were, "from the outside" as an external relation between two states that are viewed as similar. In that case, we run into the problem Husserl struggled with in his discussion of association in earlier texts. For example, in a lecture course from 1904/5 Husserl indeed describes the principles of association as combining presentations that «lack intrinsic affinity» and that are related to the objective sense of perception only

19 Husserl had recognized the importance of association as early as in the Logical Investigations. There he speaks of the «felt mutual belongingness» of experiences (Hua 19, I §4; II §34) but is not yet able to give a deep clarification of the phenomenon. In Experience and Judgment, Husserl himself refers to the discussion of indication (Anzeige) in the Logical Investigations as the «nucleus of genetic phenomenology» (HusserL 1973, 75 [§16].)

Metodo. International Studies in Phenomenology and Philosophy Special Issue, n. I, ch. 1 (2015) 
«extrinsically and indirectly» (Hua 38, 35). As Stephen Crowell has recently pointed out, this early account of association, modeled on signitive relations (which are extrinsic) actually leaves us in the dark as to what prevents these associations from being arbitrary. ${ }^{20}$ In my view, Husserl's important insight (and the advancement of his later theory over earlier attempts to capture the phenomenon of association) is that, as it were, "from inside" of the associative synthesis, i.e., in terms of how it is experienced, different moments of the emerging unified content are given as intrinsically belonging together. Association is, according to Husserl's mature account, a «purely immanent connection» (HusserL 1973, 75 [\$16]). ${ }^{21}$

Primary association displays the same correlation as all intentionality: the given articulates itself as given for consciousness. At its most concrete, this correlation manifests in affection, which is the "Ur-Stiftung" and driving force of primary association. Husserl makes it very clear that the motivational structure by which consciousness "strives for" unity is, at the same time, "pulled" by the "object" (which at the most basic level may be not more than a "prominence" in the perceptual field). In order to illustrate the force of the object's pull and in order to impress on us its essential role in the process of perception, Husserl even lends the "object" ${ }^{\prime 22}$ its own voice:

There is still more to see here, turn me so you can see all my sides, let your gaze run through me, draw closer to me, open me up, divide me up; keep on looking [at] me over again and again, turning me to see all sides. You will get to know me like this, all that I am, all my surface qualities, all my inner sensible qualities, etc. (Hua 11, 5)

[...] Draw closer, closer still; now fix your eyes on me, changing your place, changing the position of your eyes, etc. You will get to see even more of me [...] (Hua 11,7)

I said earlier that consciousness is "passive" in a double sense. Here the second sense, in which it experiences the "given" as asserting itself, comes to the fore. This does not mean that the object "causes" any events in consciousness but rather that it "motivates" certain syntheses. Besides the associative syntheses

20 Cf. CROWELl 2013, 133-135.

21 Crowell doubts that Husserl's later account solves the problems of the early one thereby challenging the significance of the difference between extrinsic significatory association and intrinsic primary association (CROWELL 2013, 139-140).

22 I put "object" into quotes because we are at this level not yet talking about full-fledged objects yet. In fact, because we are talking about the most basic beginnings of constitution, it would be more accurate to speak simply of the "non-ego", as Husserl himself does in a manuscript of 1931 (Ms. C 10 15b; also quoted by ZAHAVI 2003, 73).

Metodo. International Studies in Phenomenology and Philosophy Special Issue, n. 1, ch. 1 (2015) 
(which underlie all acts of consciousness), these also include, in the case of perception in particular, kinaesthetic ones, which are always correlated with perceptual ones. In perception, then, "unity" of coincidence arises in a "constitutive duet» (Hua 11,52) involving, on the one hand, the emerging unity of the "objectlike" sense, and, on the other hand, the autopoietic unity of the "lived body". In this "duet", pace Kant, the "object" sets the tone: an affection always "precedes the receptive action», i.e., the ego's «turning toward» the object (Hua 11, 84). In fact, the "ego" is only " "awakened" in response to an object» (Hua 11, 145). ${ }^{23}$ Or, to be more precise, the associative "Ur-stiftung" is relational. In affection, as its most concrete manifestation, the "correlational Apriori" plays out as the dynamic back-and-forth of the object's "affective force (affektive Kraft)» and the ego's «responsivity (antwortende Tätigkeit)» (Hua 11, 50). This means that consciousness is passive in yet a third sense, namely in the sense that the object in part directs the course of perception. As Donn Welton puts it, in perception my experience

is simultaneously one of mastering and being mastered, of actions and resistance, of invading and being invaded. In the case of perception I not only act but I am acted upon, I not only effect but I am caught up in a larger realm of affectivity. ${ }^{24}$

This also means that "the given" is, in Husserl's analysis, more than the "matter" of cognition. Not only does the given display "unity of coincidence" prior to the Ego's «act of putting various presentations with one another and of comprising their manifoldness in one cognition» (A77/ B103). It is itself a "player" in perception, not a mere "cause", but a "motive", as Merleau-Ponty puts it later. ${ }^{25}$

At its most rudimentary level as "non-Ego", it is constituted as simple "prominence (Abhebung)» that "takes place through fusion under contrast with respect to content» (Hua 11, 149). However, such prominences are not merely cognitive unities (e.g., of sensations), but also affective ones; «as unities for themselves they are eo ipso also for the ego, affecting it» (Hua 11, $162 \mathrm{f}$.). What is prominent has salience for consciousness. It holds «allure for consciousness

23 Of course the "ego" meant in this context is not the active Ego (for whom the expression is usually reserved). Husserl uses the term "primal ego" in the same text in which he speaks of the "non-ego" (see fn. 22). However, it is appropriate to speak of an "ego" in this "primal" sense insofar as the affected consciousness is not indifferent but "awakened" and "responsive" - even though it is not active yet.

24 WELTON 2000, 243

25 Merleau-PONTY 2002, 36.

Metodo. International Studies in Phenomenology and Philosophy Special Issue, n. I, ch. 1 (2015) 
(bewußtseinsmäßiger Reiz)»; it exercises a «pull (Zug)» on the ego (Hua 11, 148). This may set into motion an entire cognitive process, in which «the ego turns toward it attentively, and progresses from here, striving toward self-giving intuition, disclosing more and more of the self of the object, thus, striving toward an acquisition of knowledge, toward a more precise view of the object» (Hua 11, 148 f.). However, this is only the «most privileged case» (Hua 11, 151). It may also simply not be strong enough to actually attract attention (cf. Hua 11, 153, 163); or the ego may be paying attention to something else. The question of when a particular affective unity, i.e., a particular object formation, rises above the threshold of the ego's attention and which one will do so, is unpredictable - we are talking about processes of "motivation" and "awakening", and not of cause and effect. Husserl mentions noematic factors, such as the «size of contrast», but also noetic ones, such as the Ego's instincts, drives and desires that will influence the strength of any given salience (cf. Hua 11, 150). ${ }^{26}$ However, that such affective «unities must be constituted in order for a world of objects to be constituted in subjectivity at all», Husserl believes is certain (Hua 11, 162).

The fact that Husserl does not give an explanation from "first sensations", prior to association, should not be surprising. Husserl remains faithful to his early "Gestaltist" intuitions. ${ }^{27}$ The "associated" whole is prior to its parts; the notion of "bare" sensations is the result of analytic thinking (as Merleau-Ponty so forcefully reminds us in the introduction to his Phenomenology of Perception). What's more, in the living present of consciousness, the perceptual field always includes a multiplicity of such prominences; there is, as Husserl puts it, a whole «relief of salience» (Hua 11, 167). Further, that relief is always already multi-layered because it never happens, as it were, "for the first time" and never "once and for all":

every accomplishment of sense or of the object becomes sedimented in the realm of the ... dormant horizontal sphere, precisely in the manner of a fixed order of sedimentation: While at the head, the living process receives new, original life, at the feet, everything that is, as it were, in the final acquisition of the retentional synthesis, becomes steadily sedimented. (Hua 11, 178)

26 Husserl remarks on the fact that at this point the analysis slides into «a phenomenology of the so-called unconscious» (Hua 11, 154), which is obviously problematic.

27 Already in Philosophy of Arithmetic, Husserl speaks of a "unitary intuition" of an individual object, which is a "whole, with regard to the fact that subsequent analysis discovers in it a multiplicity of parts» (Hua 12, 195).

Metodo. International Studies in Phenomenology and Philosophy Special Issue, n. 1, ch. 1 (2015) 
The way in which these different layers come to bear on each other in perception is explicated by Husserl in his account of "types", which is meant to capture the sense in which the dynamic of fulfilment always already has a history. Not only has "originary association", as it were, always already happened, but it is also always already fulfilling (or disappointing) tacit expectations generated by, not necessarily immediately, preceding experiences.

In accordance with what is given to consciousness retentionally, there is "to be expected" something new on its way having a uniform style....it is characterized as in accordance with what has been [...]. (Hua 11, 186)

Perception therefore is neither a mental state, nor a mere process, but a continuous practice. The appropriate response to an affection is not a change from one mental state to another, or the inevitable unfolding of a triggered event, but precisely a "response" (for example, a shift of attention) within an ongoing practice of perception. As a practice, perception has a habitual history with an inherent normative dimension. It has a history that prefigures its presence and future of fulfillment. This history is a history of "typification". In fact, in Experience of Judgment Husserl speaks of the entire perceptual field (regarded not only synchronically, but also diachronically) as a «totality of typification (Totalitätstypik) (HuSSERL 1973, 36 [§8]). The normativity of typification - Husserl also speaks of its "concrete Apriori» (Hua 1, 114) - is indeterminate but not arbitrary; «in the flux of intentional synthesis (which creates unity in all consciousness and which, noetically and noematically, constitutes unity of objective sense), an essentially necessary conformity to type prevails» (Hua 1, 86 f.).

Our expectations may be disappointed; they may let us perceive what is not there, or not perceive what is there. However, Husserl is interested not in the question whether a single perception is veridical or not, or how it can be. He is interested, rather, in the rational progression of perception as a continuous practice, which is also a continuous practice of confirmation (Bewahrheitung). ${ }^{28}$ It is true, then, as Crowell has pointed out, that even if

it is not conceived psychologically or causally, association is not the sort of thing that can be said to succeed or fail: contents just are or are not associated as similar, continuous, or whatever, and by itself this cannot

28 «In a certain respect, the untrue, the non-being is already eliminated in passivity. A thoroughgoing consciousness of one and the same world comes into being through revisions and corrections» (Hua 11, 98).

Metodo. International Studies in Phenomenology and Philosophy Special Issue, n. I, ch. 1 (2015) 
lead to "anticipations" that may or may not be fulfilled. ${ }^{29}$

However, it is not clear that this reduces the relevant normativity of the continuous practice of perception «to covariance relations between systems of appearances in consciousness», namely between kinaesthetic and presentative sensations. ${ }^{30}$ For that correlation always already implies a reference point that surpasses both systems of appearances: the thing itself, which is the telos and as such a norm of perceptual practice. It is an ideal norm because it lies in the essence of the perceptual object to transcend any perceptions we may have of it, but it is a norm nonetheless. Practices of perception do not themselves generate the norm but they constitute different, more or less appropriate, modes of attempting to reach it and to bring it - i.e, the object, the norm - to appearance. «A being that can be legitimated, a true being in itself, lies at the basis of all of this; all error, all illusion has its norm in a hidden truth, but a truth that is to be attained» (Hua 11, 214). In passivity, this truth comes to appearance through syntheses of coinciding in which already established coincidences have normative pull; they function as "attractors", at least to the extent that they motivate senses of fulfilling (i.e., as confirming the ongoing perception) or disappointing (i.e., as challenging the ongoing perception).

For Husserl the perceptually given is thus, even insofar as it is given, far from being merely contingent. In fact, it has its own laws. «It designates a realm of the "innate" Apriori» that does not have its origin in an ego's understanding but, conversely, "without which an ego as such is unthinkable» (Hua 1, 114). Husserl believes that the necessities we actively grasp in judgments have their ultimate origin in these necessary structures of perception. What's more, the necessities of perception are apparent to us; we are aware of them passively in the ways in which we anticipate the perceptual world to be a certain way and in which we expect ourselves to be able to access it in prefigured modes of perceptual practice. To speak like some contemporary Heideggerians, we know these necessities practically in the mode of, more or less successful, "absorbed coping". Husserl's notion of syntheses of coincidence refers to the processes and practices that disclose the unities of the perceptually given in necessary ways, i.e., in ways that are essential to the perceptually given.

However, the perceptually given also always already points beyond itself at a different kind of necessity, namely the eidetic necessity of its respective essence. While for Husserl «individual existence of every sort is [...] "contingent"», for him, contingency is only "the other face" of necessity. Any

29 CROWell 2013, 140.

30 CROWell 2013, 143.

Metodo. International Studies in Phenomenology and Philosophy Special Issue, n. 1, ch. 1 (2015) 
empirical thing is contingent precisely because, while it is thus, it could be otherwise, which means "otherwise" «in respect of its essence» (Hua 3, 9). His statement, in Ideas I, that everything contingent is also "governed throughout by a fixed set of ideal laws (durchherrscht von fester Wesensgesetzlichkeit)» (Hua 3, 298) can thus be understood in at least two different senses. There are the "typical" necessities inherent in perception itself, but there are also the "essential" necessities which perception "emptily" indicates. Those too can become apparent to consciousness, namely in "eidetic intuition", which is an accomplishment of the active Ego but which nonetheless finds fulfilment in given coincidences - coincidences not of perception, but of imagination.

\subsection{Coincidence of Essences: Passivity in Husserl's Notion of Eidetic Intuition}

Husserl believes to have discovered generalities on all levels of objectivity. In fact, even on the most basic level of originary association, understood as a synthesis of the similar with the similar, the given is imbued with an air of generality insofar as this association already implies a disregarding of difference between the moments thus associated as well as a sense of affinity amongst them. The unity of what is perceptually given «is not a mere assemblage of distinct givens, but already in the passivity of its preconstitution it essentially includes a bond of internal affinity» (HUSSERL 1973, 322 [§81a]). Different moments of this affinity may be considered in their likeness, but their unity of coincidence also gives a sense of their participation in a generality which is common to both (cf. HusSERL 1973, 327 [§81c]) - a sense of "what" they are. This generality itself can become evident as an object of intuition in a process Husserl calls "eidetic intuition (Wesensanschauung)".

Any such What can [...] be "put into an idea." Experiencing, or intuition of something individual can become transmuted into eidetic seeing (ideation) [...] What is seen when that occurs is the corresponding essence, or Eidos [...] (Hua 3, 10).

Eidetic intuition thus makes explicit what is already implicit in the experience of an individual "something" as manifesting a "whatness" in addition to its "thisness"; we see it as being of a certain kind. What distinguishes Husserl's account - above all from Kant's - is that Husserl does not conceive of the "whatness" of individuals as conceptual (although he does not deny that it can be conceptualized). As Sokolowski puts it so well:

A concept works among meanings and judgments and inhabits [...] the apophantic domain, while an essence works [...] among what is

Metodo. International Studies in Phenomenology and Philosophy

Special Issue, n. I, ch. 1 (2015) 
intended through meanings. It inhabits the ontological domain. ${ }^{31}$

According to Husserl, any object, by virtue of being contingent, has «its essence (sein Wesen)»(Hua 3, 20), i.e., «its stock of essential predicables which must belong to it [...] if other, secondary, relative determinations can belong to it» (Hua 3, 9f.; my italics).

The fact that the eidos inhabits the ontological domain also means that it can be considered an object in its own right. We can not only think it, but also make it evident, i.e., "see" it. The essence that is implicit in the "whatness" of the individual can

be transformed, by methodical thinking, into a pure eidos [...] when we no more consider the essence as exemplified in this thing before us, but take it as an object sui generis that is independent of the actual and possible instantiations. ${ }^{32}$

This transformation requires, as Mohanty says, "methodical thinking". Essences are grasped in active syntheses of an Ego who is after identifying and describing those essences. Essences are therefore, in a specific Husserlian sense of the expression, «products of reason» (Hua 1, 112).

However, we do not find them as real objects in the world; they are ideal objects which we recognize «by means of subjective processes that are specifically acts of the Ego» (Hua 1, 111). However, this does not mean that we make them up or that we construct them out of thin air. We do not project them onto the world of experience. It is perhaps less misleading to call them "results" of active cognitive operations that are directed towards their identification. Like the "results" of a scientific experiment, they are, if the experimental method is adhered to correctly, not taken as "created" by those operations but as "discovered" in them (cf. Hua 1, 108). This sense of discovery, that is, the insight that an essence (e.g., "perceptual object as such") actually regulates the domain attributed to it and in the ways identified in eidetic intuition (e.g., as transcending any of its possible perceptions) is based on an identification between what is intended as such an essence and what is given in intuition as the fulfillment of this intention. This is precisely why Husserl insists that we must be able to "see" an essence. By being intuitable as "given" (and not merely constructed) the essence find its only phenomenologically legitimate validation, namely the fulfillment of what otherwise be at best an empty concept of it.

31 SOKOLOWSKI 1974, 68.

32 MOHANTY 1997, 11.

Metodo. International Studies in Phenomenology and Philosophy Special Issue, n. 1, ch. 1 (2015) 
This fulfillment, however, can only be understood if we recognize that eidetic intuition has not only active but also passive moments. Essences are disclosed to us independently from any efforts we might make to identify and determine them. "Seeing" essences is, for Husserl, as quotidian and mundane as "seeing", i.e., "intuitively" grasping, that $2+2=4$, or that the spatial object in front of me must have more sides than the ones I can presently see. «The truth is that all human beings see "ideas," "essences," [...] - except that from their epistemological standpoint they interpret them away» (Hua 3, 41). It might be difficult to accept that we do because our epistemological preconceptions might let us believe that we cannot (e.g., because we are convinced that we can only "see" what is given to us perceptually). The possibility of eidetic intuition might therefore be, as Husserl puts it in a phrase that spectacularly underplays the degree of disbelief with which his idea has been met by critics to this day, «strange to the tradition-bound» but «phenomenologically evident» (Hua 1, 114).

What is evident here is not only that we can grasp such evidences, but that we are able to distinguish between the active identification of an essence and its fulfillment in the way it is "given". In fact, "identification" here means the identification of what we suppose something to be with what it gives itself as being. Thus, «anything built by activity necessarily presupposes, as the lowest level, a passivity that gives something beforehand» (Hua 1, 112) ${ }^{33}$ Only due to this correlation can anything actively be recognized as that which is also passively given, and thus not as "merely" constructed. Only due to the possibility of a passive synthesis of coincidence is it possible, in Husserl's view, to "demonstrate" the validity of an active synthesis and to do phenomenology as a "rigorous science" with a "purely intuitive [...] mode of demonstration [that] excludes all "metaphysical adventure", all speculative excesses» (Hua 1, 166).

Husserl gives quite explicit descriptions of the process of eidetic intuition. Generally speaking, its aim is to identify the invariant, i.e., essential, features of objects or experiences in a process of "free variation". We ask:

33 Husserl's distinction between a synthesis of identification and a synthesis of coincidence has a certain affinity, which he himself notes, with Kant's distinction between a synthesis of recognition (in the concept) and a synthesis of apprehension (in intuition) in the Adeduction. However, it must again be noted that Husserl disagrees with Kant both insofar as he sees no reason for a fundamental separation between the intellectual and the intuitive and insofar as he can find no evidence for the claim that intuitive synthesis must necessarily be "subject to" laws of the understanding.

Metodo. International Studies in Phenomenology and Philosophy Special Issue, n. I, ch. 1 (2015) 
In such free variations of a paradigm,... what remains kept as the invariant, the necessary universal form, the essence-form, without which something of this sort ... would be entirely unthinkable as an example of its kind? (Hua 9, 72)

While in his early writings, e.g., in the second Logical Investigation, he still finds it relatively unproblematic to take some real individual as the starting point for such variations he later emphasizes the risks of distortion this brings. Hence he comes to insist that the "pure eidos" is only discoverable if we

so to speak, shift the actual perception into the realm of non-actualities, the realm of the as-if, which supplies us with "pure" possibilities, pure of everything that restricts to this fact or to any fact whatever. (Hua 1, $104)^{34}$

The aim is not to arrive at a mere generalization from empirical facts, but at the "pure eidos", which prescribes for any of its possible actualizations how it can be what it is "with absolute "essential universality", and with "essential necessity"» (Hua 1, 105). To this aim, Husserl believes, we must begin with an arbitrary example, that is, with an example that is precisely not wilfully selected and not taken from experience - a merely possible token of the type whose essence one is attempting to identify and describe. Only its arbitrariness, into which it is liberated by the deliberate shift from actual examples to pure possibilities, prevents the investigator from selecting examples that would favour a certain result. While, as we have seen, Husserl believes that essences are always already disclosed in the experience of real individuals, the method of "eidetic intuition" is conceived by Husserl as a process by which the essence thus disclosed "must from the outset be freed from its character of contingency» (HuSSERL 1973, 340 [§87]). We must, as Sokolowski puts it, «flush the eidos» out of the contingent variants. ${ }^{35}$

The ego is active here in more than one sense. It follows an explicit cognitive interest due to which «what differentiates the variants remains indifferent to us» (HusserL 1973, 341 [§87]). However, due to the transition into the realm of pure possibility it is also liberated by an «act of volition» to produce variants that transgress the boundaries of actual experience (ibid.). The ego is thus not just active, as it is in all judgments, but it is free. Husserl speaks of a «specific freedom of essential seeing...in which we are not bound by the conditions of unanimity in the same way as in the progress of experience» (HuSSERL 1973, 344

34 See also: Hua 9, 74f.; Husserl 1973, 424.

35 SOKOLOWSKI 1974, 79.

Metodo. International Studies in Phenomenology and Philosophy Special Issue, n. 1, ch. 1 (2015) 
[§87d]). The arbitrariness of the variants and the freedom of essential seeing culminate in the intuition of an open infinity, namely the "remarkable and truly important consciousness of "and so on, at my pleasure"» which signals that «it is a matter of indifference what might still be joined to it» - the essence has become evident (HuSSERL 1973, 342 [§87b]).

The insight that no further variants will make a difference to the now evident essence is pivotal. It turns the variants from being seen as examples that specify an empirical generality, which remains open to correction by further variants, into becoming evident as instances that are specified by an a priori eidos, which prescribes, prior to and independently from any of its particular actualizations, the laws to which all of its instances must conform. ${ }^{36}$ The whole point of Husserl's insistence that this "turn" is intuited is a point about the validity of that insight. Methodologically, everything depends for Husserl on the claim that he already makes in the Logical Investigations, namely that «this we do not merely think, but we see it to be true» (Hua 19, 831 [VI §65]).

Whatever one might think of this fundamental conviction, ${ }^{37}$ this "seeing it to be true", if it is to be "scientific" in the Husserlian sense, depends on passive moments in eidetic intuition..$^{38}$ Active syntheses of identification always receive their validation, i.e., their fulfillment, in passive syntheses of coinciding. These passive syntheses do not, therefore, exclusive belong to the pre-predicative sphere, which is a comparatively uncontroversial claim, but also to the highest levels of reason, namely the levels of a priori cognition. In eidetic intuition they disclose a necessary unity in the free variants. Husserl is very clear about this:

In this transition from image to image, from the similar to the similar, all the arbitrary particulars attain overlapping coincidence in the order

36 Cf. Welton 2005, 45.

37 What to Husserl is arguably the single most important methodological point of his entire phenomenological work also is precisely what disqualifies his work, and perhaps all phenomenology, in the eyes of others. Julius Kraft, a contemporary critic of Husserl, had it in mind when he described phenomenology as a «philosophy that throws overboard critical judgment for imaginary intuitions and even renews long obsolete quibblings about essence and existence in the style of the middle ages», which in his eyes makes it at best an «inexact empirical science with metaphysical frippery,» at worst a manifestation of the dangerous «revulsion of the 20th century against reason, knowledge, and truth» (KRAFT 1975). It is also what led Theodor Adorno to speak of the dangerous "irrationalism" that lies at the heart of phenomenology (ADORNO 1982, 200). Both Kraft and Adorno - who saw in Scheler and especially Heidegger the confirmation of their worst fears in this regard - only expressed concerns that are shared also by many contemporary critics. These concerns still deserve profound consideration.

38 Ichiro Yamaguchi already emphasized this point (YAMAGUCHI 1982, 62ff.).

Metodo. International Studies in Phenomenology and Philosophy Special Issue, n. I, ch. 1 (2015) 
of their appearance and enter in a purely passive way, into a synthetic unity in which they all appear as modifications of one another and then as arbitrary sequences of particulars in which the same universal is isolated as an eidos (HUSSERL 1973, 343 [§87b] - my italics).

If this could not happen in this way, then eidetic intuition simply would not be possible.

Only in this continuous coincidence does something which is the same come to congruence, something which henceforth can be seen purely for itself. This means that it is passively preconstituted as such and that the seeing of the eidos rests in the active intuitive apprehension of what is thus preconstituted - exactly as in every constitution of objectivities of the understanding, and especially of general objectivities. (Ibid.)

Within the phenomenological framework, this is the only guard against philosophical speculation - the only reason we are not left with empirical science, logic or fantastical speculation as our only alternatives. While for Kant everything hangs on the "transcendental unity of apperception", for Husserl it all hangs on the fortunate circumstance that «we need not ourselves actively and expressly bring about the overlapping» coincidences that disclose necessary unities of contingent manifolds, «since [...] it takes place of itself in a purely passive way» (ibid.).

However, there is not only a constraining condition for eidetic phenomenology, there is also an enabling one. This is the freedom of the imagination, of which Husserl therefore claims that it is the "vital element" of phenomenology qua eidetic science (Hua 3, 132). For the passive coincidence emerging from eidetic variation is intuited as "necessary" only insofar as it withholds the "tests" and "challenges" of free imagination. Sokolowski speaks of this as the "negative necessity» of eidetic intuition.

This is the negative aspect of free variation: the insight that removal of certain moment in a variant, or the addition of certain moments to it, destroys the individual - either totally, as a being, or at least as an instance of the eidos we are trying to isolate. ${ }^{39}$

The coincidence «is not registered as an eidos until we have run into the impossibility» of imagining it otherwise although we are imagining freely. Thus it is only in free imagination that the boundaries of the imaginable emerge as constraints that are not of a contingent but of a necessary nature. In this

39 SOKOLOWSKI 1974, 80.

Metodo. International Studies in Phenomenology and Philosophy Special Issue, n. 1, ch. 1 (2015) 
function, imagination as free phantasy liberates from actual experiences and matters of fact; it thus facilitates eidetic, i.e., a priori intuitions. In this sense, it can be said to have a "transcendental" function for eidetic phenomenology. It can even be said to have a mediating function. However, it does not mediate between two separate stems of cognition (as is the case in Kant's framework) but between the contingency of matters of fact and the necessity of eidetic truths.

\section{Conclusion}

For Kant «we can know a priori of things only what we ourselves put into them» (Bxviii). This is because all necessary structure that the given might display it has received a priori through the forms of cognition that lend unity to various synthesis involved. Besides this, the given is radically contingent. As sensation it has no order; as appearance its laws are not its own. Husserl's very different method shows him a very different world, namely a world that is already given as "governed throughout by a fixed set of ideal laws (durchherrscht von fester Wesensgesetzlichkeit)» (Hua 3, 298). Obviously, the kinds of "necessities of coincidence" that emerge from Husserl's phenomenology would have not impressed Kant, who would have had to dismiss them as crude empirical generalities that at best simply reflect empirically what is really a "transcendental affinity". Equally, Kant's failure to get into view the deep structures of constitution and his inability to grasp a critical and nonspeculative meaning of "intellectual intuition", renders his philosophy inadequate for Husserl.

Shared convictions always shine through - above all, a commitment to transcendental philosophy as a project of "rigorous science" that attempts to identify necessary laws in a contingent world in reference to the necessary conditions of their knowability. However, this difference is irreconcilable: Kant thinks of a necessary unity as a unity that receives its necessity "top down" from the "highest point" of reason, i.e., from the transcendental unity of apperception. Husserl, on the contrary, thinks of unity "laterally" as a unity of "coincidence (Deckung)", which enables a priori cognition not only of necessities that «reason produces itself according to its own plan» (B xiii), but also into necessities reason genuinely discovers.

Metodo. International Studies in Phenomenology and Philosophy Special Issue, n. I, ch. 1 (2015) 


\section{Abbreviations}

Hua Husserliana. Edmund Husserl - Gesammelte Werke. Nijhoff, Den Haag, 1950ff.

\section{References}

Adorno, T.W. 1982. Against Epistemology: A Metacritique. Oxford: Blackwell.

Crowell, S. 2013. Normativity and Phenomenology in Husserl and Heidegger. Cambridge: Cambridge University Press.

Husserl, E. 2001a. Logical Investigations, vols. 1 and 2, trans. J. N. Findlay, by D. Moran, London: Routledge. [Cited according to the English pagination since it contains no German pagination in the margins. To enable easy access in German, section numbers are added]

- 2001b. Analyses Concerning Passive and Active Synthesis, trans. A. Steinbock. Dordrecht: Kluwer. [Cited according to German pagination, Hua 11 and 31 respectively, since this edition contains material from both Husserliana volumes]

- 1983. Ideas Pertaining to a Pure Phenomenology and to a Phenomenological Philosophy, First Book, trans. F. Kersten. The Hague: Martinus Nijhoff. [Cited according to German pagination in Hua 3]

- 1977. Phenomenological Psychology, trans. J. Scanlon. The Hague: Martinus Nijhoff. [Cited according to German pagination in Hua 9]

- 1975. Cartesian Meditations, trans. by D. Cairns. Dordrecht: Kluwer. [Cited according to German pagination in Hua 1]

- 1973 Experience and Judgment, trans. J. Churchill and K. Ameriks. Evanston: Northwestern. [Cited according to the English pagination. To enable easy access in German, section numbers are added]

- 1970. "The Origin of Geometry», in The Crisis of European Sciences and Transcendental Phenomenology, trans. D. Carr. Evanston: Northwestern University Press, 353-378.

- 1969. Formal and Transcendental Logic, trans. D. Cairns. The Hague: Martinus Nijhoff. [Cited according to German pagination in Hua 17]

KANT, I. 1996. Critique of Pure Reason, trans. Werner Pluhar. Indianapolis: Hackett. [Cited simply with original pagination A/B]

KRAFT, J. 1957². Von Husserl zu Heidegger: Kritik der phänomenologischen Philosophie. Frankfurt am Main: Verlag 'Óffentliches Leben'.

Merleau-Ponty, M. 2002. Phenomenology of Perception, trans. C. Smith. New York: Routledge. 
Mohanty, J.N. 1997. Phenomenology: Between Essentialism and Transcendental Philosophy. Evanston: Northwestern University Press.

SOKOLOWSKI, R. 1974. Husserlian Meditations. Evanston: Northwestern University Press.

STEINBOCK, A. 2001. «Translator's Introduction», in HUSSERL 2001, XV-LXV.

StumPF, C. 1890. Tonpsychologie, vol. 2, Leipzig: Hirzel.

Welton, D. 2000. The Other Husserl. Bloomington: Indiana University Press.

YamaguchI, I. 1982. Passive Synthesis und Intersubjektivität bei Edmund Husserl.

Dordrecht: Kluwer.

ZAHAVI, D. 2003. Husserl's Phenomenology. Stanford: Stanford University Press.

Metodo. International Studies in Phenomenology and Philosophy Special Issue, n. I, ch. 1 (2015) 